
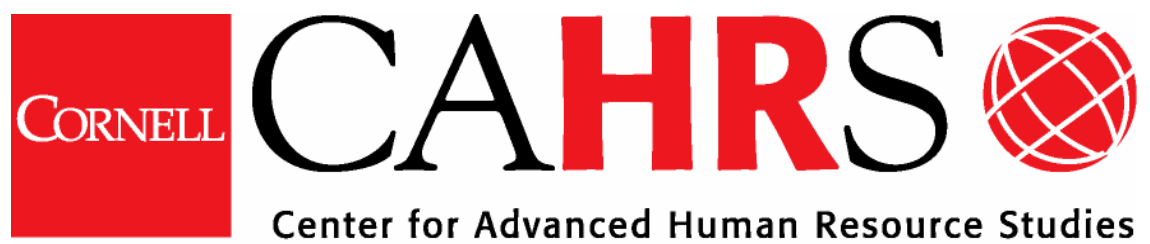

Center for Advanced Human Resource Studies

CAHRS / Cornell University 187 Ives Hall

Ithaca, NY 14853-3901 USA

Tel. 607 255-9358

www.ilr.cornell.edu/CAHRS/

Worhing Paper gealeg

\title{
The Relationship Between HR Practices and Firm Performance: Examining Causal Order
}

Patrick M. Wright

Timothy M. Gardner

Lisa M. Moynihan

Mathew R. Allen

Working Paper 04-06

CORNELL ilr School of Industrial and Labor Relations 


\title{
The Relationship Between HR Practices and Firm Performance: Examining Causal Order
}

\author{
Patrick M. Wright \\ Department of HR Studies \\ School of ILR \\ Cornell University \\ Ithaca, NY 14853-3901 \\ pmw6@cornell.edu \\ Timothy M. Gardner \\ Marriott School of Management \\ Brigham Young University \\ Provo, UT 84602 \\ tmg13@byu.edu \\ Lisa M. Moynihan \\ London Business School \\ London, UK \\ Imoynihan@london.edu \\ Mathew R. Allen \\ Department of HR Studies \\ School of ILR \\ Cornell University \\ Ithaca, NY 14853-3901 \\ mra26@cornell.edu
}

February 3, 2005

\section{http://www.ilr.cornell.edu/cahrs}

This paper has not undergone formal review or approval of the faculty of the ILR School. It is intended to make results of Center research available to others interested in preliminary form to encourage discussion and suggestions.

Most (if not all) of the CAHRS Working Papers are available for reading at the Catherwood Library. For information on what's available link to the Cornell Library Catalog: http://catalog.library.cornell.edu if you wish. 


\begin{abstract}
Significant research attention has been devoted to examining the relationship between HR practices and firm performance, and the research support has assumed HR as the causal variable. Using data from 45 business units (with 62 data points), this study examines how measures of HR practices correlate with past, concurrent, and future operational performance measures. The results indicate that correlations with performance measures at all three times are both high and invariant, and that controlling for past or concurrent performance virtually eliminates the correlation of HR with future performance. Implications are discussed.
\end{abstract}




\section{The Relationship Between HR Practices and Firm Performance: Examining Causal Order}

The desire of human resource $(\mathrm{HR})$ practitioners to demonstrate the value of what they do for the rest of the organization has a long history. Drucker (1954) referred to "personnel" managers as constantly worrying about "...their inability to prove that they are making a contribution to the enterprise," (p. 275). This has been echoed more recently by Tom Stewart, who described HR leaders as being "...unable to describe their contribution to value added except in trendy, unquantifiable and wannabe terms..." (Stewart, 1996, p. 105)

In response to these longstanding and repeated criticisms that HR does not add value to organizations, the past 10 years has seen a burgeoning of research attempting to demonstrate that progressive HR practices result in higher organizational performance. Huselid's (1995) groundbreaking study demonstrated that a set of HR practices he referred to as High Performance Work Systems (HPWS) were related to turnover, accounting profits, and firm market value.

Since then, a number of studies have shown similar positive relationships between HR practices and various measures of firm performance. For instance, MacDuffie (1995) found that "bundles" of HR practices were related to productivity and quality in his sample of worldwide auto assembly plants. Delery and Doty (1996) found significant relationships between HR practices and accounting profits among a sample of banks. Youndt, Snell, Dean and Lepak (1996) found that among their sample of manufacturing firms, certain combinations of HR practices were related to operational performance indicators. More recently Guthrie (2001) surveyed corporations in New Zealand and found that their HR practices were related to turnover and profitability. This vein of research has been summarized by Huselid and Becker who stated "Based on four national surveys and observations on more that 2,000 firms, our judgment is that the effect of a one standard deviation change in the HR system is $10-20 \%$ of a firm's market value" (Huselid \& Becker, 2000; p. 851, emphasis added) 
Certainly, the existing research suggests a positive relationship between HR and performance. However, contrary to Huselid and Becker's (2000) claim, this body of work tends to lack sufficient methodological rigor to demonstrate that the relationship is actually causal in the sense that HR practices, when instituted, lead to higher performance. Little, if any, research has utilized rigorous designs to test the hypothesis that employing progressive HRM systems actually results in higher organizational performance in a causal sense.

The purpose of this study is to provide a more rigorous examination of the causal order in the HR practice - organizational performance relationship. It uses a unique sample of autonomous business units within the same company and explores the relationships between HR practices and past, concurrent, and future measures of operational and financial performance.

\section{A Causal Examination of the HR - Performance Relationship}

For research to better explore the relationship between HR practices and profitability, two issues need to be addressed: The causal chain through which HR impacts profitability, and the conditions necessary for making valid causal inferences. Given the empirical research linking HR practices to quite distal outcomes such as profitability, an understanding of and empirical support for the intervening mechanism adds to the validity of causal inference. In addition, conditions necessary for drawing causal inferences have been thoroughly examined within the philosophy of science literature, yet little of that discussion has been integrated into the literature on the relationship between HR practices and firm performance. We address each of these below.

\section{Demonstrating the HR Causal Chain}

Demonstrating the impact of HR practices on firm profitability requires two related conditions. First, researchers must define theoretically or conceptually how HR practices can or should impact performance. Then, once this model has been defined, researchers must gather 
data to demonstrate the validity of the proposed model. Research has been much more focused on defining the chain than in actually testing it.

Numerous authors have suggested the need to better understand the processes through which HR practices might impact performance (Becker \& Huselid, 1998; Dyer \& Reeves, 1995; Hutchison, Kinney, \& Purcell, 2002; Wright \& Gardner, 2003). In an early effort to explicate this relationship, Dyer and Reeves (1995) reviewed the existing HR - performance research and proposed that measures of performance could be broken down into four categories. First, most proximal to the HR practices, "employee outcomes" deal with the consequences of the practices on employees such as their attitudes and behavior, particularly behaviors such as absenteeism and turnover. Less proximal, "organizational outcomes" focus on more operational measures of performance such as productivity, quality, and shrinkage; many or all of which would be precursors to profitability. Even more distal, "financial/accounting outcomes" refer to the actual financial performance measures such as expenses, revenues, and profitability. Finally and most distal to the HR practices, "market-based outcomes" were those reflecting how the financial markets valued a firm, particularly stock price or variations of it. They proposed that these outcomes represented a causal order; HR practices impacted employee outcomes, which consequently influenced organizational outcomes, thereby affecting financial outcomes, ultimately resulting in market-based outcomes.

Becker and Huselid (1998) provided one of the more detailed models of the relationship between HR practices and firm performance offered to date. In essence, this model suggests that business strategies drive the design of the HR system. The HR system directly impacts employee skills and motivation and the structure and design of work. These factors influence employee behavior, which translates into improved operating performance. This drives profits and growth, which result in market value.

While numerous conceptual models of the HR - performance relationship may exist, the empirical work testing these models has not progressed as significantly. Rogers and Wright 
(1998) reviewed the empirical research on the HR - Performance relationship surveying 29 studies reporting 80 effect sizes (i.e., reported statistical relationships between HR practice and performance measures). They found that very few studies had examined human resource outcomes, many had used accounting and financial market measures, and the largest number of effect sizes was observed for organizational outcomes (productivity, quality, service, etc.). However, very little of this empirical research has examined multiple potential linkages (Wright \& Gardner, 2003).

To truly demonstrate the causal impact of HR practices on profitability, one would need to see how they impact both proximal outcomes (e.g., organizational outcomes) and more distal outcomes (e.g., profits). We should note that given sample size constraints, our study does not attempt to test a full mediation model of the HR causal chain. However, we do include both proximal (operational performance) and more distal (profitability) measures of performance.

\section{Conditions for Inferring Cause}

While not obvious to most, the timing of measurement in much of the research on the impact of HR practices on performance has precluded drawing firm causal conclusions of this relationship. Cook and Campbell (1979) provide an in-depth analysis of how philosophers of science have approached the issue of demonstrating a causal relationship. Based on the work of John Stuart Mill, they propose three criteria for inferring cause: Covariation between the presumed cause and effect, the temporal precedence of the cause, and the ability to control or rule out alternative explanations for a possible cause and effect connection.

With regard to covariation, they suggest that demonstrating cause requires that the effect be present when the cause is present, and the effect absent when the cause is absent. Temporal precedence requires that, at the level of molar relationships, the proposed cause must exist in time prior to the proposed outcome. Finally, while not always possible, they suggest a need to control for all other variables that might cause the focal outcome. While such conditions do not necessarily "prove" cause, they provide a basis for drawing more valid causal inferences. 
Importantly, Cook and Campbell (1979) note that the ability to infer causal connections is instrumental for human decision making. They suggested that the most interesting causal relationships are ones where decision makers exert some control over the putative cause. In such situations, they can manipulate the putative cause in order to influence the proposed outcome. This fits quite nicely with the basic assumption and goal of the research on the HR performance relationship. This stream of research seeks to demonstrate a relationship between HR practices and performance in an effort to provide decision makers with the causal inferences necessary to justify developing and implementing these practices in order to increase performance. Consequently, this vein of research, to fulfill its ultimate goal, must provide research that maximizes the validity of the proposed causal inferences.

\section{Research on the HR - Performance Causal Relationship}

It is important to note that such research built predominantly around survey methodologies, can never match the ability to demonstrate both temporal precedence and control of alternative explanations that exist in laboratory experiments. So we do not suggest that any survey design can ultimately "prove" cause. However, we do believe that existing research, while consistently demonstrating covariation, has seen largely inadequate attention paid to temporal precedence and/or alternative explanations.

With regard to temporal precedence, a number of studies have appeared that utilize purely cross sectional survey methodologies. Such designs entail a single data collection effort where the same respondent provides information for both assessments of their current HR practices and their firms' performance. We refer to these designs as being "post predictive" because they are actually predicting past performance (i.e., performance up to the point of the survey). For instance, Delaney and Huselid (1996) used data on both HR practices and performance collected via phone interviews. Interestingly, such designs ask respondents for their firm's current HR practices, but measure their past performance (i.e., performance up until 
the point of the response) presenting a logical inconsistency for arguing that HR practices cause performance.

In addition to the logical inconsistency inherent in such cross-sectional designs, some of the studies accepted as being somewhat predictive are not true predictive designs. For instance, Ichniowski, Shaw and Prennushi (1997) used monthly performance data from steel finishing lines over a five-year period. However, they measured HR practices by asking respondents after the five-year production period to recall what the HR systems were in place at different points during the time frame. Similarly, Guthrie (2001) used performance data from 1996/7 but asked respondents during that time to report the practices that existed during 1995/96. We refer to these designs as being "retrospective" because they ask respondents to remember the HR practices that existed at some point in the past, prior to the measure of performance. Given the potential problems noted by others (Gerhart et al., 2000; Wright et al. 2001) with regard to unreliability of single rater reports of HR practices compounded with the memory requirements to report practices that existed from one to five years in the past, such retrospective designs preclude drawing confident causal conclusions.

Other studies have gathered contemporaneous HR practice and performance data and we refer to these studies as being "contemporaneous". For instance, Delery and Doty (1996) gathered HR practice data during 1992, and used the year-end performance data. Because the year-end data includes performance from months prior to and concurrent with the HR practice measure, it is difficult to draw firm causal conclusions using this methodology.

Only a few studies have explored if practices assessed at one point in time were related to subsequent firm performance. Such designs are the only true "predictive" designs. Huselid (1995) gathered both contemporaneous and subsequent year performance data, and reported only the subsequent year data in his study in order to provide more conservative effect size estimates. Youndt et al. (1996) related HR practices to plant performance assessed 2 years 
later. Youndt and Snell (1995) also related their assessments of HR practices to performance assessed 3 years later.

Finally, very few studies to date have attempted to test whether firm performance predicts future HR practices or vice versa. A study conducted by the consulting firm Watson Wyatt (2002) used data on 51 corporations with HR practice and financial performance scores for 1999 and 2001. They found that the 1999 HR practices correlated .41 with 2001 financial performance, but 1999 financial performance correlated only .19 with 2001 HR practices, thereby concluding that this demonstrated that HR practices were "leading indicators" of future financial performance.

In one of the most extensive efforts to examine causal order, Huselid and Becker (1996) compared cross-sectional and panel estimates to determine which direction the causal arrow pointed. They found that longitudinal estimates were substantially smaller than cross sectional estimates, and when using the most appropriate statistical analyses, non-significant. However, they found that after making the necessary statistical corrections for measurement error, the data seemed to indicate that previous HR practices predicted future corporate financial performance. In addition, as Gerhart (2004) notes, using fixed effects estimates can result in lower effect sizes than cross sectional estimates because of measurement error problems. While Huselid and Becker corrected for unreliability in their fixed effects estimates, they did not correct for unreliability in the cross sectional estimates. Upon doing so, Gerhart found that the cross-sectional coefficient (.240) was nearly twice as large as the comparable fixed effects coefficient of .125 , suggesting that there may be an omitted variables problem.

More recently, Guest, Michie, Conway, and Sheehan (2003) related HR practices to both past and subsequent objective productivity and profitability data as well as current subjective productivity and financial performance estimates among a sample of 366 companies in the U.K. They found that HR practices were related to higher profitability but not productivity using the objective performance measures, but that after controlling for past performance, the significant 
relationship with profitability disappeared. They concluded that their results confirm an association between HRM and performance, but failed to demonstrate that HR causes higher performance.

In order to illustrate how these designs have been used in past HR - performance research, Table 1 provides a list of studies on HR and performance, and categorizes these studies in terms of (a) the design used (post predictive, retrospective, contemporaneous, or predictive), (b) whether or not a significant relationship was observed between HR and performance, and (c) whether or not the study attempted to explore the causal order empirically.

TABLE 1. Human Resource Management Practice Questions ${ }^{\text {a }}$

Selection

1. Applicants undergo structured interviews (job related questions, same questions asked of all applicants, rating scales) before being hired.

2. Qualified employees have the opportunity to be promoted to positions of greater pay and/or responsibility within the company.

3. Applicants for this job take formal tests (paper and pencil or work sample) before being hired.

Training

4. On average how many hours of formal training do employees in this job receive each year? ${ }^{b}$

Pay for Performance and Performance Evaluation

5. Employees in this job regularly (at least once a year) receive a formal evaluation of their performance.

6. Pay raises for employees in this job are based on job performance.

7. Employees in this job have the opportunity to earn individual bonuses (or commissions) for Participation productivity, performance, or other individual performance outcomes.

8. Employees in this job are involved in formal participation processes such as quality improvement groups, problem solving groups, roundtable discussions, or suggestion systems.

9. Employees in this job have a reasonable and fair complaint process.

\footnotetext{
a With the exception of those marked, the response option for these questions was "Yes, No, I don't know."

${ }^{\mathrm{b}}$ Response option was "Hours

${ }^{\mathrm{c}}$ Response options for these questions were: "Never, Annually, Quarterly, Monthly, Weekly, Daily."
} 


\section{Research on the Attitude - Performance Causal Relationship}

The notion of causality is not limited to the HR-performance relationship. In fact, many proposed models of this relationship posit that attitudinal variables such as employee engagement, job satisfaction or organizational commitment might act as mediators. Recent research on these affective variables and performance at the unit level of analysis provides interesting insights and additional evidence that the directionality of cause may be suspect.

For instance, Ryan, Schmit, and Johnson (1996) examined the relationship between unit employee satisfaction and a number of organizational performance measures with branches of a financial service organization. While they found employee satisfaction was related to employee turnover, customer satisfaction, and 60-day delinquency rate within each of successive years, they unexpectedly found that customer satisfaction in year 1 predicted employee satisfaction in year 2, but not vice versa.

More recently, Koys (2001) examined the relationship between the HR outcomes of employee satisfaction, employee turnover, and citizenship behavior organizational outcomes of profits and customer satisfaction among 28 branches of a restaurant chain. He found that the HR outcomes in one year more strongly the organizational outcomes in the following year than the organizational outcomes in one year predicted the HR outcomes in the following year.

In a significant meta-analysis of the attitude-performance relationship, Harter, Schmidt, \& Hayes (2002) examined the relationship between employee satisfaction-engagement and business unit outcomes such as customer satisfaction, productivity, profit, employee turnover and accidents. Their results showed a consistent set of strong relationships with all these outcomes. They conclude that changes in management practices that increase employee satisfaction may increase business-unit outcomes. While they do not specifically test for the causal direction, they note that some of the studies used predictive designs, and acknowledge that future research should continue to focus on causality and directionality issues. 
In a more pessimistic study, Schneider, Hanges, Smith, and Salvaggio (2003) used job satisfaction data from a consortium of companies gathered over a set of 8 years. They gathered financial performance information (ROA) and market performance data (EPS) over the same period of time in order to assess the causal direction. Using multiple time lags (1 year, 2-yr, etc.) they found significant and stable relationships for 3 of the 7 scales. However, their results indicated that Overall Job Satisfaction and Satisfaction with Security were more strongly predicted by past performance (using both ROA and EPS) than vice versa, and that the third scale, Satisfaction with Pay, exhibited a reciprocal relationship with the performance measures.

Finally, Fulmer, Gerhart, and Scott (2003) examined the question of if the "100 Best Companies to Work For" are actually better performers. These authors based their analysis on the idea that having a superior employee relations climate would result in higher motivation and productivity, and reduced turnover which would translate into financial performance. In an extremely creative study, they examined differences between a set of the 1998100 Best and (a) a matched set of peer companies from each member's industry, and (b) a Value Weighted Index of firms from the NYSE/AMEX/NASDAQ stock listings over a 6 year time frame including 3 years prior to the announcement of their status on the list and the 3 years following. We should note that our categorization would actually suggest that while the authors were correct in defining these years prior to and following the announcement (the list came out onJanuary 12 , 1998) the actual employee satisfaction data was gathered during the prior year (1997), making results with regard to that year really a "concurrent" study. Nonetheless, this study provides some evidence of the potential for the causal arrow to point either way. While they did find that the 100 Best companies outperformed their comparison groups on most of the dependent variables in 1997 and 1998, on at least one variable (annual return to shareholders, 1996, Table 3) they also outperformed their competitors. In addition, while problematic because it included the1997 year, which was actually concurrent with the data collection, the 100 Best companies outperformed their comparison groups on the cumulative returns from 1995-1997. Thus, while it 
is clear, as the authors note, that investing in these 100 Best companies would provide a higher return than investing in the comparison companies, this might have been true even before they were noted for their strong employee relations climate.

These studies indicate that significant uncertainty exists as to the extent to which attitudes at the unit level impact unit performance, unit performance impact attitudes, or the relationship exhibits dual causality. This suggests the need for further research because, as Harter et al. (2002) suggest, "The most convincing causal evidence comes not from one study but from a body of research and a multitude of types of evidence..."

\section{Summary}

As can be seen by this detailed analysis of the designs, some of the seminal studies in the HR - performance literature fail to provide predictive designs that allow drawing more confident causal inferences. In addition, the studies that specifically set out to address the causal nature of the relationship have provided, at best, somewhat mixed results. Finally, studies examining the causal order in the employee attitude (those expected to be strongly impacted by HR practices) and organizational outcomes have also produced mixed results. This may not be problematic if no valid alternative explanations for the relationship have been proposed. However, a number of alternative causal models have been proposed.

\section{Alternative Causal Models for the HR - Performance Relationship}

Universally assumed in the HR - performance literature is a causal model wherein HR practices, when implemented effectively, result in higher organizational performance. However, Wright and Gardner (2003) offered three alternative explanations for the observed covariation between HR practices and firm performance.

First, "reverse causation" would suggest that, rather than HR practices causing performance, performance causes HR practices. This model suggests that high performing organizations, by their nature possess slack resources. Firms that are profitable may share these profits with employees in a number of ways. They may provide higher pay and benefits, 
may invest in offering more training and development opportunities, may develop more extensive selection systems, and may allow employees to participate in teams, quality circles, and other forms of empowerment activities. In fact, a number of the HR practice items more logically demonstrate a reverse causation effect. Items such as the percentage of total pay which is variable, the differences in percent merit increases between high and low performers, and the number of hours training received are heavily influenced by the past and current financial performance of a firm. Firms facing financial difficulties reduce their variable pay (profit sharing and stock options have little or no value), merit increases (and thus the difference between high and low performers), and training budgets (reduce the number of hours they train employees).

Consequently, studies that do not attempt to assess temporal precedence (through using a predictive design that uses a performance measure collected following the HR practice measure) may not provide the data necessary for making valid causal inferences. Even studies that are predictive in design may still not allow complete confidence in drawing causal conclusions. As Huselid and Becker (1996) showed, if financial performance also predicts HR practices, then both predictive designs, or designs that examine cross lagged correlations (such as the Watson Wyatt study) may show relationships between past HR practices and future firm performance, without truly proving that it is the HR practices leading to performance, rather than vice versa.

Second, a "spurious" relationship might exist if there were an actual true covariation between the measures of HR practices and performance, yet there were no direct causal relationship between the two variables. In this case, it may be that a third variable is causing both variables resulting in their respective covariation. For instance, it could be that effective leaders cause organizational performance, and they also treat employees well through progressive HR practices. Again, studies that do not control for a full set of variables that might cause performance may lack the data necessary for making valid causal inferences. 
Finally, "implicit performance theories" might suggest that there may be no true relationship between HR practices and performance, but one may be observed empirically due to respondents' implicit performance theories. This explanation suggests that the information processing requirements for respondents to know and report all HR practices across all jobs across all units, across the globe are too great, and consequently, they respond to the HR practice measure based on their knowledge of the firm's performance (i.e., "we're a high performing firm so we must do all these HR things"). In fact, a study by Gardner and Wright (2002) presented executives and graduate students with fictitious descriptions of high and low performing companies and found evidence that their reports of HR practices can be influenced by knowledge of the company's past performance. Thus, studies gathering concurrent HR practice and performance (or retrospective HR) data, particularly if both measures come from the same respondent, may have HR practice measures that are contaminated by respondents' implicit performance theories.

This discussion is not to suggest that any one study can adequately address all of the conditions necessary for drawing causal conclusions. It does however, point to the fact that the current research base does not provide the data necessary for drawing causal conclusions implicitly or explicitly driving current research and practice.

This study will attempt to address at least some of these issues with regard to drawing valid causal conclusions regarding the relationship between HR practices and firm performance. First, it uses a number of variables that comprise a logical chain through which we expect that HR practices will impact profitability, including human resource (organizational commitment), operational (productivity, quality, shrinkage, and workers compensation) and financial (expenses and profits) performance measures. Second, the performance data is collected over time, allowing us to explore the relative relationships between our focal variables (HR and Organizational Commitment) and the performance variables assessed prior to, concurrent with, and following the assessment of these focal variables. Finally, while it does not control for all 
potential alternative causes of the performance variables, the unique sample of autonomous business units within the same company control for a number of extraneous variables (industry, product lines, revenues, number of employees, etc.) that are often difficult to control in other studies.

Consistent with past research, we offer our proposed conceptual model for how HR practices impact profitability in Figure 1. This figure illustrates that HR practices have their most immediate impact on organizational commitment. These variables result in improved operational performance (productivity, quality, shrinkage, workers compensation), which impacts expenses, resulting ultimately in profitability. This model corresponds rather closely with Dyer and Reeves (1995) model (employee, organization, and accounting/financial outcomes). This figure is not a model to be tested, but rather a guide for understanding the analyses regarding causal direction.

Figure 1 The Predictive Model of HR Practices Impact on Organizational Outcomes

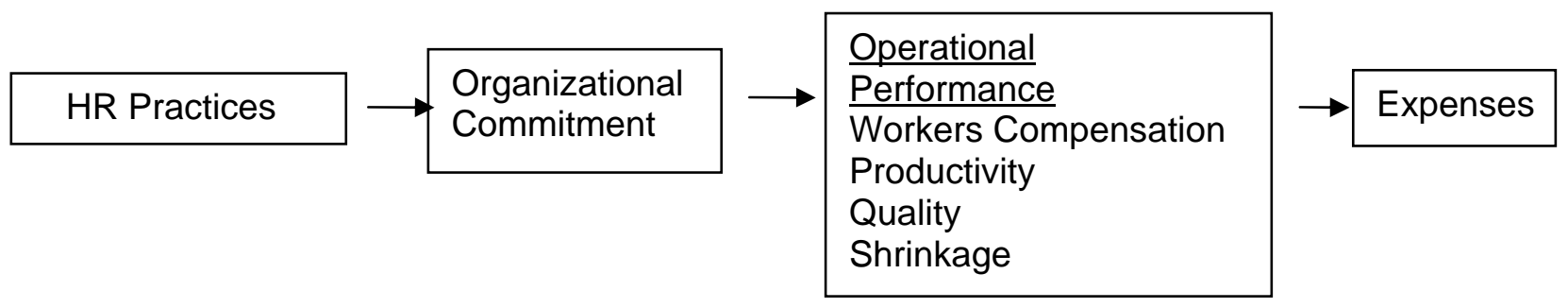

At the outset we should note that the purpose of this paper is not to argue that HR practices do not have any impact on firm performance. Rather, it is to argue that (a) past research does not provide an adequate basis for inferring cause, and (b) past research may have resulted in inflated estimates of any causal impact that does exist. 


\section{Method}

\section{Overview.}

This study consisted of examining the relationships between both HR practices and organizational commitment and various operational and financial measures of performance. Survey data collected from multiple employees per business unit were used to measure HR practices and organizational commitment and their covariation with archival measures of previous, concurrent, and subsequent organizational performance measures collected in the 6 month intervals.

\section{Sample.}

The sample consisted of 45 business-units of a large food service corporation with operations in the United States and Canada. The data was collected over 2 fiscal years (19982000), and because a subset $(n=17)$ of the business units participated in the survey in both years, there are 62 data points. ${ }^{1}$ In each of the business units, we used the survey responses from employees in 3 core jobs: MA (Merchandising Associates, i.e., salespersons), warehouse employees, and delivery drivers. This sample consisted of approximately $20 \%$ of the employees in each business unit. These three jobs represent those that have the most direct impact on the customer from sale to delivery. The MA's work with customers to determine their product needs and place their orders, warehouse employees acquire the necessary products from the warehouse, and the delivery drivers deliver these products to the customers.

Each company data point was derived from surveys from an average of 39.02 MAs, 38.66 warehousers, and 35.00 drivers for a total of 112.68 employees per company and a total of 6986 employees across the 62 data points. In order to eliminate the possibility of common method variance (or percept-percept correlations which are biased by collecting two measures from the same source using the same method at the same time), we used the reports of HR

\footnotetext{
${ }^{1}$ For each of these 17 cases we treated them as independent observations using the corresponding past, simultaneous, early post and late post measures. Consequently the late post measures for these cases in year 1 also served as the past measures in year 2. Because the 17 business units created the situation where the observations were not all independent, we re-ran the analyses with only the 45 independent observations. The results did not differ significantly from those presented here, so in the interest of higher power, we used the full data set.
} 
practices from half of the respondents from each organization and the reports of organizational commitment from the other half of the respondents.

This company's management philosophy emphasizing structural ways to create an entrepreneurial environment presents a unique opportunity to study the relationship between HR and performance in a controlled field setting. First, the company tries to keep every business between $\$ 350$ million and $\$ 700$ million in revenues with a corresponding employee count of between 250 and 600 employees. If a company grows beyond the $\$ 700$ million mark, it is then divided into two companies. This creates a sample where size (both in terms of revenues and employees) is strongly controlled. Also, the basic products and information technology are largely uniform across all of the business-units. While regional differences may result in different volumes and mixes of products, the products available for sale are uniform. Similarly, while localized changes might be made to the information technology, the basic operational systems are largely uniform. Thus, again the sample largely controls for performance differences due to products and technology.

However, while size, technology and products provide little opportunity for variance, considerable variance exists with regard to HR strategies. Guided by the corporate principle of "earned autonomy," business-units are largely free to manage their employees however they see fit. A minimal level of uniformity in HR practices exist with regard to legally mandated benefits, but the majority of HR practices (e.g., specific selection processes and practices, pay systems, performance management systems, training and development strategies and practices) are left to the business-units to design, develop, and implement. Corporate control over the business units comes from monitoring the operational and financial results that we report here. This is analogous to the "financial" controls as opposed to "strategic" controls discussed in the corporate strategy literature (see Rowe and Wright, 1997). Thus, this sample provides a unique opportunity to study the HR - performance relationship where many sources of extraneous variance are controlled through design (thus negating the need for statistical 
controls), while the major focus of variance is with regard to the phenomenon of interest: HR practices.

Measures.

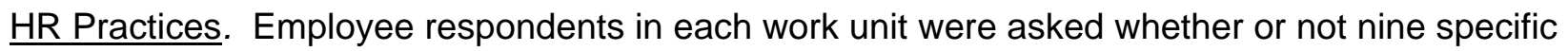
HR practices existed for their job category ("Yes," "No," and "I don’t know"). "Yes" responses were coded as 1; "No" responses were coded as zeros. "I don’t know" responses were classified as "No" and coded as zeros. See Table 1 for the complete listing of the HR practice items used in this study. The choice of the items was based on a compromise between what the researchers wanted to examine and what the company was willing to allow to be asked. We were allowed to add some actual HR practice items to the survey in return for providing a reduced fee (the company was originally only interested in assessing the climate), but the company representatives refused to allow us to ask some questions that they deemed too sensitive in terms of potentially priming employees to wonder why they did not have these practices (e.g., gainsharing, profit-sharing, etc.). In the end, we had items that represented the major areas of HR practices (selection, pay for performance, training, and participation).

One training item was originally written in a different response format than the rest of the HR practice items. This item was "On average, how many hours of formal training do employees in this job receive each year?" This item was re-coded to comply with the yes/no dichotomous response format of the other practice items. If the number of training hours entered is equal to or greater than 15 , that response was be coded as " 1 " = yes. Hours below 15 were coded as "0" = no, as such low levels arguably do not represent significant investment in employee training.

Consistent with previous research, we used an additive index of these HR practices (e.g. MacDuffie, 1995, Youndt, et al. 1996). Because there was no reason to believe that these practices should be conceptualized as a uni-dimensional construct (see Delery, 1998), interrater reliability was deemed to be the most appropriate reliability assessment. Intra-class correlations 
were computed for this scale at the organizational level. For each individual, a ratio was calculated of the number practices they stated were present divided by 9 . The business unit index of HR practices was created by taking the mean of this ratio for the half of the employees providing information about this measure. Hoffman (2002) notes that when constructs are objective ones that are being assessed by multiple respondents (such as with HR practices), one is only interested in obtaining a reliable estimate of the aggregate phenomena. These measures illustrated that using a single respondent [ICC(1) which assesses the reliability of a single respondent measure] would result in extremely low reliability, but that by using multiple respondents [ICC(2) which assesses the reliability of using aggregated multiple respondents] the reliability of the measures is more than adequate (average item $\operatorname{ICC}(1)=.06$, average item $\operatorname{ICC}(2)=.77 ;$ scale $\operatorname{ICC}(1)=.13$, scale $\operatorname{ICC}(2)=.89)$.

Organizational Commitment. Five items were used from two different organizational commitment scales (Meyer \& Allen, 1997; Porter et al, 1974). Sample items include "I feel a strong sense of belonging to this organization", "I am willing to work harder than I have to in order to help this company succeed", and "I am proud to be working for this company." Items were averaged to create one index per person and were then aggregated to the business level using half the sample of employees providing information about commitment. Again, aggregating over respondents resulted in good reliability $(\alpha=.86, \operatorname{ICC}(1=.07, \operatorname{ICC}(2)=.81)$. The ANOVAs used to calculate the ICCs were significant at the .001 level suggesting a level of agreement about organizational commitment at the business unit to aggregate individual scores into a mean commitment score.

Performance. Six measures of performance were provided from archival company records. These measures represent the major performance measures tracked by the corporate headquarters as indicators of a businesses success. ${ }^{2}$ "Workers Compensation" was the

\footnotetext{
${ }^{2}$ One of the reviewers correctly noted that a number of problems exist with using ratio measures in regression. The preferred method for controlling for the denominator is by entering it in to the regression equation rather than computing it as a denominator. However, the corporation only provided us with data in its already computed ratio form.
} 
workers compensation expenses incurred during the six months divided by sales; the lower the number the better. "Quality" was measured as number of pieces per error where each piece represents a carton of product. "Shrinkage" was measured as inventory loss including loss due to spoilage, warehouse outs, inventory adjustments, cycle count adjustments, warehouse damage, delivery shorts, delivery damage, samples shrinkage, and sales return damage as a percentage of sales. "Productivity" was assessed as payroll expenses for all employees divided by the number of pieces; the lower the number the better (i.e., it measures "payroll per piece"). "Operating Expenses" consisted of all relevant business operating expenses including warehouse, occupancy, delivery, selling, data processing, and G\&A expenses as a percentage of sales. Finally "Profitability" was assessed as the operating pre-tax profit of the business-unit as a percentage of sales where operating pre-tax profit was calculated as Sales - (Cost of Goods Sold + Operating Expenses + Cash Discounts).

Each measure was for a six month period and included 9 month to 3 months prior to the survey administration (past), 3 month prior and 3 months after the survey administration (concurrent), 3 to 9 months after survey administration (early post) and 9 to 15 months after the survey administration (late post).

\section{Results}

The means (centered to disguise the data), SD's, and intercorrelations are presented in Table 2. 
TABLE 2

Descriptive Statistics and Correlations of All Variables ${ }^{a, b}$

\begin{tabular}{|c|c|c|c|c|c|c|c|c|c|c|c|c|c|c|c|}
\hline & s.d. & 1 & 2 & 3 & 4 & 5 & 6 & 7 & 8 & 9 & 10 & 11 & 12 & 13 & 14 \\
\hline 1. HR Practice Index & .11 & & & & & & & & & & & & & & \\
\hline 2. $\quad$ Commitment & .27 & .57 & & & & & & & & & & & & & \\
\hline 3. $\quad$ Profitability (past) & .93 & .23 & .26 & & & & & & & & & & & & \\
\hline 4. Profitability (concurrent) & .83 & .32 & .34 & .75 & & & & & & & & & & & \\
\hline 5. $\quad$ Profitability (early post) & .92 & .33 & .29 & .78 & .95 & & & & & & & & & & \\
\hline 6. Profitability (late post) & .88 & .33 & .31 & .67 & .93 & .93 & & & & & & & & & \\
\hline 7. Operating Expenses (past) & .02 & -.21 & -.26 & -.49 & -.49 & -.51 & -.42 & & & & & & & & \\
\hline 8. Operating Expenses (concurrent) & .01 & -.20 & -.25 & -.49 & -.51 & -.49 & -.45 & .94 & & & & & & & \\
\hline 9. Operating Expenses (early post) & .01 & -.25 & -.27 & -.49 & -.52 & -.53 & -.48 & .94 & .97 & & & & & & \\
\hline 10. Operating Expenses (late post) & .01 & -.16 & -.18 & -.42 & -.48 & -.47 & -.47 & .87 & .95 & .95 & & & & & \\
\hline 11. Shrinkage (past) & .0001 & -.38 & -.34 & -.49 & -.48 & -.42 & -.41 & .32 & .36 & .32 & .30 & & & & \\
\hline 12. Shrinkage (concurrent) & .0001 & -.35 & -.30 & -.39 & -.39 & -.35 & -.35 & .29 & .30 & .27 & .24 & .86 & & & \\
\hline 13. Shrinkage (early post) & .0001 & -.30 & -.26 & -.41 & -.44 & -.41 & -.37 & .32 & .32 & .31 & .26 & .81 & .93 & & \\
\hline 14. Shrinkage (late post) & .0001 & -.29 & -.22 & -.26 & -.39 & -.35 & -.34 & .23 & .22 & .21 & .18 & .59 & .72 & .82 & \\
\hline 15. Productivity (past) & .28 & -.08 & -.25 & -.36 & -.34 & -.35 & -.26 & .82 & .76 & .77 & .73 & .20 & .17 & .19 & .10 \\
\hline 16. Productivity (concurrent) & .27 & -.03 & -.20 & -.38 & -.35 & -.34 & -.29 & .77 & .80 & .79 & .80 & .22 & .16 & .16 & .06 \\
\hline 17. Productivity (early post) & .28 & -.07 & -.23 & -.34 & -.33 & -.33 & -.29 & .77 & .81 & .82 & .83 & .19 & .16 & .17 & .08 \\
\hline 18. Productivity (late post) & .29 & -.06 & -.18 & -.36 & -.36 & -.35 & -.33 & .72 & .78 & .78 & .84 & .25 & .19 & .19 & .08 \\
\hline 19. Quality (past) ${ }^{\mathrm{C}}$ & 198.5 & .50 & .46 & .49 & .49 & .48 & .48 & -.21 & -.16 & -.22 & -.17 & -.56 & -.48 & -.45 & -.36 \\
\hline 20. Quality (concurrent) & 238.7 & .46 & .40 & .39 & .47 & .46 & .46 & -.08 & -.06 & -.09 & -.04 & -.59 & -.56 & -.52 & -.43 \\
\hline 21. Quality (early post) & 234.2 & .48 & .38 & .44 & .50 & .51 & .50 & -.14 & -.11 & -.16 & -.12 & -.57 & -.54 & -.53 & -.45 \\
\hline 22. Quality (late post) & 291.0 & .49 & .37 & .47 & .53 & .53 & .52 & -.27 & -.30 & -.32 & -.30 & -.46 & -.40 & -.42 & -.40 \\
\hline 23. Workers Comp. (past) ${ }^{\mathrm{C}}$ & .001 & -.15 & -.56 & -.35 & -.31 & -.31 & -.27 & .34 & .27 & .30 & .23 & .27 & .25 & .21 & .29 \\
\hline 24. Workers Comp. (concurrent) & .001 & -.46 & -.43 & -.28 & -.27 & -.23 & -.25 & .31 & .31 & .33 & .22 & .36 & .23 & .25 & .28 \\
\hline 25. Workers Comp. (early post) & .001 & -.43 & -.50 & -.38 & -.36 & -.34 & -.35 & .41 & .37 & .41 & .31 & .28 & .18 & .20 & .26 \\
\hline 26. Workers Comp. (late post) & .001 & -.26 & -.43 & -.33 & -.30 & -.34 & -.30 & .40 & .32 & .35 & .28 & .16 & .10 & .12 & .20 \\
\hline \multicolumn{16}{|c|}{$\begin{array}{l}\text { a } \text { To maintain the confidentiality of company information all variables were centered and have a mean of zero. } \\
\text { b Except as described below } n=62 ; \text { Coefficients }>|.20| \text { are significant at } p<.10 ;>|.24| \text { at } p<.05 ;>|.30| \text { at } p<.01\end{array}$} \\
\hline
\end{tabular}


TABLE 2 (Continued)

Descriptive Statistics and Correlations of All Variables ${ }^{a}$

\begin{tabular}{lllllllllll}
15 & 16 & 17 & 18 & $19^{\mathrm{c}}$ & 20 & 21 & 22 & $23^{\mathrm{c}}$ & 24 & 25 \\
\hline
\end{tabular}

1. HR Practice Index

2. Commitment

3. Profitability (past)

4. Profitability (concurrent)

5. Profitability (early post)

6. Profitability (late post)

7. Operating Expenses (past)

8. Operating Expenses (concurrent)

9. Operating Expenses (early post)

10. Operating Expenses (late post)

11. Shrinkage (past)

12. Shrinkage (concurrent)

13. Shrinkage (early post)

14. Shrinkage (late post)

15. Productivity (past)

16. Productivity (concurrent) $\quad .93$

17. Productivity (early post) $\quad .92 \quad .97$

18. Productivity (late post) $\quad .85 \quad .94 \quad .96$

19. Quality (past)

$\begin{array}{llll}-.20 & -.16 & -.18 & -.20\end{array}$

20. Quality (concurrent)

21. Quality (early post)

$\begin{array}{lllll}-.01 & .02 & .01 & -.03 & .89\end{array}$

$\begin{array}{llllll}-.02 & .00 & -.02 & -.05 & .85 & .92\end{array}$

22. Quality (late post)

23. Workers Comp. (past)

24. Workers Comp. (concurrent)

25. Workers Comp. (early post)

$\begin{array}{lllllll}-.11 & -.13 & -.18 & -.21 & .64 & .69 & .79\end{array}$

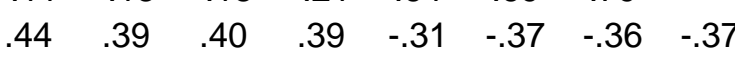

$\begin{array}{lllllllll}.21 & .18 & .22 & .18 & -.22 & -.28 & -.29 & -.35 & .74\end{array}$

26. Workers Comp. (late post)

$\begin{array}{llllllllll}.33 & .31 & .35 & .31 & -.34 & -.36 & -.38 & -.44 & .79 & .86\end{array}$

$\begin{array}{lllllllllll}.44 & .38 & .41 & .36 & -.17 & -.20 & -.16 & -.26 & .59 & .51 & .70\end{array}$

While somewhat redundant, Tables 3 (HR practices) and 4 (organizational commitment) provide these same relationships in a way that enables the reader to better understand the causal connections. Columns 1 through 4, display the correlations between the focal variable and each of the past, concurrent, early post and late post performance variables. Columns 5 through 8 show the partial correlations with future performance (early and late) controlling for past (columns 5 and 6) and concurrent (columns 7 and 8) performance, respectively. 
Table 3

Correlation Between HR Practice Index and Performance Measures ${ }^{a}$

\begin{tabular}{|l|c|c|c|c|c|c|c|c|}
\hline & 1 & 2 & 3 & 4 & 5 & 6 & 7 & 8 \\
\cline { 2 - 9 } & Past & $\begin{array}{c}\text { Con- } \\
\text { current }\end{array}$ & $\begin{array}{c}\text { Early } \\
\text { Post }\end{array}$ & $\begin{array}{c}\text { Late } \\
\text { Post }\end{array}$ & $\begin{array}{c}\text { Early Post } \\
\text { Controlling } \\
\text { For Past } \\
\text { Performance }\end{array}$ & $\begin{array}{c}\text { Late Post } \\
\text { Controlling } \\
\text { For Past } \\
\text { Performance }\end{array}$ & $\begin{array}{c}\text { Early Post } \\
\text { Controlling } \\
\text { For } \\
\text { Concurrent } \\
\text { Performance }\end{array}$ & $\begin{array}{c}\text { Late Post } \\
\text { Controlling } \\
\text { For } \\
\text { Concurrent } \\
\text { Performance }\end{array}$ \\
\hline 1. Profitability & $.23^{\dagger}$ & $.32^{* *}$ & $.33^{* *}$ & $.33^{* *}$ & $.25^{*}$ & .24 & .07 & .07 \\
\hline $\begin{array}{l}\text { 2. Operating } \\
\text { Expenses }\end{array}$ & $-.21^{\dagger}$ & -.20 & $-.25^{*}$ & -.16 & -.15 & .04 & -.21 & .10 \\
\hline 3. Shrinkage & $-.38^{* *}$ & $-.35^{* *}$ & $-.30^{*}$ & $-.29^{*}$ & .01 & -.10 & .08 & -.06 \\
\hline 4. Productivity & -.08 & -.03 & -.07 & -.06 & .00 & .02 & -.21 & -.09 \\
\hline 5. Quality & $.50^{* * 4}$ & $.46^{* *}$ & $.48^{* *}$ & $.49^{* *}$ & $.02^{\mathrm{b}}$ & $.22^{\mathrm{b}}$ & .16 & $.26^{*}$ \\
\hline 6. Workers Comp. & $-.15^{\mathrm{b}}$ & $-.46^{* *}$ & $-.43^{* *}$ & $-.26^{*}$ & $-.21^{\mathrm{b}}$ & $-.09^{\mathrm{b}}$ & -.08 & -.04 \\
\hline
\end{tabular}

${ }^{\mathrm{a} E x c e p t}$ as noted, $\mathrm{n}=62$.

${ }^{\mathrm{b}}$ For these analyses, $\mathrm{n}=45$

$\dagger p<.10$

$* p<.05$

$\star * p<.01$

TABLE 4

Correlation Between Organizational Commitment and Performance Measures ${ }^{a}$

\begin{tabular}{|c|c|c|c|c|c|c|c|c|}
\hline & 1 & 2 & 3 & 4 & 5 & 6 & 7 & 8 \\
\hline & Past & $\begin{array}{l}\text { Con- } \\
\text { current }\end{array}$ & $\begin{array}{l}\text { Early } \\
\text { Post }\end{array}$ & $\begin{array}{l}\text { Late } \\
\text { Post }\end{array}$ & $\begin{array}{l}\text { Early Post } \\
\text { Controlling } \\
\text { For Past } \\
\text { Performance }\end{array}$ & $\begin{array}{l}\text { Late Post } \\
\text { Controlling } \\
\text { For Past } \\
\text { Performance }\end{array}$ & $\begin{array}{l}\text { Early Post } \\
\text { Controlling } \\
\text { For } \\
\text { Concurrent } \\
\text { Performance }\end{array}$ & $\begin{array}{l}\text { Late Post } \\
\text { Controlling } \\
\text { For } \\
\text { Concurrent } \\
\text { Performance }\end{array}$ \\
\hline 1. Profitability & $.26^{*}$ & $.34^{\text {*x }}$ & $.29^{*}$ & $.31^{x / 4}$ & .15 & .19 & -.10 & -.03 \\
\hline $\begin{array}{l}\text { 2. Operating } \\
\text { Expenses }\end{array}$ & $-.26^{*}$ & $-.25^{*}$ & $-.27^{\star}$ & -.18 & -.09 & .09 & -.16 & .17 \\
\hline 3. Shrinkage & $-.34^{\text {** }}$ & $-.30^{*}$ & $-.26^{*}$ & $-.22^{\dagger}$ & .04 & -.03 & .08 & -.002 \\
\hline 4. Productivity & $-.25^{*}$ & -.20 & $-.23^{\dagger}$ & -.18 & -.002 & .08 & -.14 & .05 \\
\hline 5. Quality & $.46^{* \times b}$ & $.40^{\text {*x }}$ & $.38^{\text {**x }}$ & $.37^{* x}$ & $.03^{b}$ & $.11^{\mathrm{b}}$ & .03 & .15 \\
\hline $\begin{array}{l}\text { 6. Workers } \\
\text { Comp. }\end{array}$ & $-.56^{* * \mathrm{~b}}$ & $-.43^{\star *}$ & $-.50^{* *}$ & $-.43^{* *}$ & $-.27^{\dagger \mathrm{b}}$ & $-.19^{b}$ & $-.28^{*}$ & $-.28^{*}$ \\
\hline
\end{tabular}


In order to test the basic model proposed in Figure 1, we first report the bivariate correlations using the concurrent measure of organizational commitment and the early post performance measures. As can be seen in Table 2, HR practices correlated highly with concurrent organizational commitment $(r=57 ; p<.01)$. Table 3 (column 3 ) shows that the HR index was also appropriately correlated with all but one of the early post operational performance measures including shrinkage $(r=-.30, p<.05)$, quality $(r=.48, p<.01)$, and workers compensation $(r=-.43, p<.01)$. HR practices were unrelated to our measure of early post productivity $(r=-.07, n s)$. The HR practice index also correlated significantly with early post expenses $(r=-.25 ; p<.05)$ and profits $(r=.33 ; p<.01)$. Similarly, as can be seen in Table 4 (column 3), organizational commitment correlated strongly with the operational performance measures productivity $(r=-.23, p<.10)$, shrinkage $(r=-.26, p<.05)$, quality $(r=.38, p<.01)$, and workers compensation $(r=-.50, p<.01)$ as well as expenses $(r=-.27 ; p<.05)$ and profits $(r$ $=.29 ; p<.05$ ). The results were similar using the late post measures (column 4 of both Tables 3 and 4), indicating support for the basic model.

While these results show that past HR practices predict future performance, they may be biased (and even misleading) if the causal arrow points in the opposite direction (e.g., performance is relatively stable and it causes HR practices). Thus, the next set of analyses examine the comparative relationships using past, concurrent, and post (early and late) measures. Starting with Table 3, comparing columns 1 and 2 with columns 3 and 4 shows that the correlations between HR practices and the performance measures vary little over time. The same comparisons in Table 4 display similar results in that the correlations between commitment and the performance measures vary little over time. On a positive note this suggests that relationships observed in concurrent studies may adequately reflect what would be observed in predictive studies. On the negative side, however, these results provide just as 
much support for the proposition that performance causes commitment and HR practices as it does the reverse.

Finally, not surprisingly given the stable correlations discussed previously, controlling for past or concurrent performance tends to reduce the relationships drastically, usually to the level of non-significance. Looking at Table 3 (columns 3 and 4), 9 of the 12 bivariate correlations between HR and the two post performance measures were significant. However, when controlling for the past performance on each of the focal variables (columns 5 and 6), only one correlation remains significant, and controlling for concurrent performance results in only one significant correlation. Turning to Table 4 (columns 3 and 4), 8 of the 12 bivariate correlations between organizational commitment and the two post performance measures were significant at the .05 level. However, after controlling for past performance, (columns 5 and 6 ), none of the correlations remained significant, and only 2 correlations remained significant when controlling for concurrent performance (columns 7 and 8). These results suggest that the proposition that HR practices cause higher organizational performance should be, at best, tentative, and great caution should be exercised in interpreting past $\mathrm{HR}$ - performance research that suggests this relationship.

\section{Discussion}

Research on the relationship between HR practices and performance has provided a firm foundation from which the next generation of research can build. While models of the process through which HR practices impact performance have progressed, they have not been tested empirically. In addition, research has not attended to the methodological rigor necessary to suggest causality. Consequently, the existing research base does not provide as firm a foundation for drawing valid causal inferences. This study suggests that such causal inferences should be drawn with extreme caution. 
The basic causal model positing that HR practices impact organizational commitment, operational performance, expenses, and profits was supported in a predictive sense. HR practices correlated strongly, positively and most often significantly with operational and financial measures observed later (both early and late). Taken alone, these results would provide more support for the notion that implementing progressive HR practices will result in improved operating and financial performance (Dyer \& Reeves, 1995; Becker and Huselid, 1998).

However, when comparing these relationships with those between HR practices and past or concurrent performance, caution flags arise. The relative consistency across all these time periods suggest that the causal order could just as easily be reversed. These results essentially mirror those of Guest et al (in press) who found that in some cases, the correlations with past performance exceeded those with future performance. Certainly they point to the fact that even predictive studies that simply explore the relationship with future performance may be misleading.

Finally, the drastic reduction in observed relationships that occurs when controlling for past or concurrent performance provides further impetus for exercising extreme caution in inferring a direct causal impact of HR on performance. Among the significant correlations (i.e, the ones which would lead to the conclusion that HR causes performance) from Table 3 (HR Performance) and Table 4 (OC - performance), considerable reductions occur. Specifically, when using the early post measure the average significant correlation is .36 which is reduced by 23 and 24 correlation points when controlling for past and simultaneous performance, respectively. Using the late post, the average significant correlation of .34 is reduced by 18 and 23 points, respectively. In Table 4, when using the early post performance measures, the average significant correlation of .34 is reduced by 22 and 21 points when controlling for past and simultaneous performance respectively. Using the late post performance measures, the 
average significant correlation of .37 is reduced by 21 and 22 points respectively. Again, this coincides with Guest et al's (in press) research demonstrating the drastic reduction to nonsignificance of the effects of HR on performance once past performance has been controlled. Again, these results spark cautious interpretation among even predictive studies.

By no means do these results suggest that HR practices do not have a positive impact on performance. Neither do they provide any more support for concluding that performance causes HR practices than they do for concluding that HR practices cause performance. They do, however, raise interesting questions regarding the true causal relationship between HR practices and performance. This leads us to speculate on some potential explanations for findings such as ours and Guest et al's (in press).

One possibility is that the data observed here, relatively consistent positive relationships over time, may indicate a non-recursive model. Such a model suggests dual causation; business units that perform well, invest more in HR practices, and this investment pays off in increased performance. If this is the case, then it does not negate the value in implementing progressive HR practices, but it does suggest that the observed payoff may be far less than the estimates provided in past research (e.g., Huselid, 1995; Huselid \& Becker, 1996; 2000).

A second explanation for these results may be that the relationship is spurious, with both $\mathrm{HR}$ and performance variables being caused by some third variable. For instance, it may be that, as previously discussed, the business units with effective leaders (presidents) both treat people well (through the HR practices) and drive higher business performance. Or, for instance, recently many corporations have sought to build "High Performance" cultures (Wright, Snell, * Pedersen, in press). Such a culture seeks to both engage employees emotionally to the firm, and to encourage them to maximize their performance. Because such cultures sought to be built in part by aligning the HR systems, one cannot easily tease out whether both HR practices 
and performance emanate from the culture, or the culture and performance emanate from the HR practices.

Third, one could hypothesize that the observed relationships result from the temporal stability of both sets of variables. For instance, HR practices tend to be intractable, and very difficult to change (Gerhart \& Milkovich, 1990; Snell \& Dean, 1994). Thus, when measuring HR practices at one point in time, one is likely capturing the practices that have existed for a number of years. If, in fact, these practices do result in higher performance, then the measure at one point in time would still be strongly related to both past and future performance. In this case, our "past" performance measure may actually be a "post" performance measure. In addition, the performance measures are quite stable over time. The correlations across the 4 time periods ranged from .67 to .95 for profitability, .87 to .97 for expenses, .59 to .93 for shrinkage, .85 to .96 for productivity, .64 to .92 for quality, and .51 to .86 for workers compensation. Consequently, past research using post-predictive or concurrent designs may display similar results to predictive designs. Again, the point is not to argue that these results "prove" reverse causation, but to point out the problem with drawing firm causal conclusions from past research data that is not valid for drawing causal inferences (ala Huselid \& Becker's (2002) quote listed at the beginning of this paper).

However, interestingly, the results do not seem to differ whether using the HR practices measure (assumed to be extremely stable) or the organizational commitment (assumed to be a bit more variable over time). Our results indicated that the correlations between commitment and the various performance measures are almost invariant over time, and that they became non significant when controlling for past or concurrent performance. This differs somewhat from the results of Koys (2001) who found that employee satisfaction in year 1 was more strongly related to profits in year 2 than the reverse. However, he did find that when controlling for other HR outcomes in one equation, and for those outcomes and past performance in another 
equation, employee satisfaction did not predict profits. Again, if HR practices strongly influence commitment, and the practices have existed for considerable time, there should also be some stable variance in commitment. However, we note simply that our results seem to show suspicion in drawing causal order conclusions whether using a stable HR predictor measure (practices) or a more variable predictor (commitment), and also seem to be consistent using both operational (shrinkage, productivity, quality, workers compensation costs) and profitability (expenses, profit) measures of performance.

An additional finding stemmed from a question raised by one of the reviewers regarding differences in variance in HR practices at different performance levels. In an exploratory analysis we divided the firms into quartiles on each of the 24 performance measures (6 measures at 4 different times), and examined the Standard Deviations for each of the quartiles. Surprisingly we found that greater variance existed in HR practices at the bottom quartiles than at the top quartiles. This seems to indicate two things. First, high performing companies seem to almost universally use a high level of HR practices (a high mean and low SD). However, having a high level of HR practices does not ensure high performance. The low performing companies, although having a low mean, also had a high SD, indicating that some of them must have been engaging in lots of HR practices. This leads to the second implication, that perhaps something is moderating the relationship between HR practices and performance. In other words, it seems that low HR practices are associated with low performance, but high HR may only be associated with high performance under certain conditions. Again, this may lead to the potential missing variable discussed above. Perhaps effective leaders or high performance cultures that are supported by HR practices tend to exhibit high performance, but simply transplanting a set of HR practices into a low performance culture or under an ineffective leader may not have the intended effect. 
These results also suggest some interesting implications for future research. Future research should focus on study designs which are better able to demonstrate the causal order to show that HR practices, when implemented correctly, can positively generate higher firm performance. At a minimum, this calls for focusing on gathering data at multiple points in time as was done in both this study and the Huselid and Becker (1996) study. Our current sample of business units with data at both points $(n=17)$ is too small for providing any stable results. However, we continue to conduct the climate survey, the number of participating business units continues to grow, and the company continues to provide the performance data. Thus, we are hopeful that future waves of data collection will provide an ability to examine how units that actually change their HR practices experience corresponding performance changes.

Another approach to teasing out the causal direction in the HR - firm performance relationship may be the use of quasi-experimental designs. Cook and Campbell (1979) discuss how quasi-experimentation can provide data that enables researchers to more confidently draw causal conclusions. For instance, the company we studied uses the climate data in part to persuade business leaders to implement better HR practices. One could identify companies that have gone through drastic changes in their HR practices and match them with companies who did not change their practices. These two samples could then be compared with regard to their subsequent performance. While such designs do not prove causation, they can help enable researchers to better understand the causal nature of the relationship between HR practices and firm performance.

\section{Limitations}

A few limitations must be considered in interpreting these results. First, while this is one of only a few studies that have actually examined how measures of HR practices relate to past performance, the time lag between the previous performance measure and the measure of HR was not great (3-9 months). Certainly it is possible that the practices reported were likely in 
place during the timeframe comprising this past performance measure. However, this illustrates the potential vacuousness of cross-sectional, or even lagged studies that examine the impact of HR practices on performance. The cross sectional relationship may exist, but there is no way to know the causal direction. Thus, while the short lag does not prove reverse causation, it certainly demonstrates that empirically, this is just as likely as the oft-hypothesized causal order.

Second, because the study was conducted within one organization, one could question the generalizability of the results. We would note that generalizability is not the goal of all research. Some research, such as this, is aimed primarily at testing theoretical predictions rather than trying to develop generalizable empirical results. What our study demonstrates is that in a cross sectional study finding a relationship between HR practices and performance, the results could also support a reverse causation explanation. Again, the goal is not to conclude that reverse causation explains all past research, nor to argue that HR practices do not impact performance, but simply to provide results that spur researchers to be more creative in the design of research in this area. Better future research designs will provide more conclusive evidence of the true causal order.

Finally, we must recognize the potential for an unmeasured variables problem. While the single corporation/multiple business unit design allows real controls over a number of variables, because these business units are geographically distinct, it may be that local labor markets and economic conditions might vary considerably across the companies. Interestingly, however, if one explores how that might play out, the most likely effect would be to support the reverse causation effect. For instance, if it is the local markets that greatly impact profitability (e.g. markets with higher socioeconomic conditions result in those companies having naturally higher profits), then any unmeasured variable effect (i.e., the relationship between HR and performance is due to this variable) would require that these companies use their excess profits 
to build HR systems. One would be hard pressed to hypothesize that companies investing in HR practices produces greater geographical socioeconomic conditions.

\section{Conclusion}

Past research has provided extensive data on the positive relationship between HR practices and organizational performance in an effort to demonstrate a positive impact of HR practices. This study has attempted to both explicate the issues with regard to drawing causal conclusions within this vein of research, and to provide empirical data to explore some of these issues. The study demonstrates that HR practices are strongly related to future performance, but that they are also strongly related to past performance, causing caution in making any causal inferences. While one could accurately interpret our results as showing HR practices to be part of a "high performance" organization, they certainly do not provide proof that these practices cause that high performance. Consequently, our study points to the need to design and conduct studies that are better able to examine the extent to which implementing progressive HR practices will result in improved operating and financial performance. Such research will provide for decision makers a more convincing business case for the need to properly manage human resources 


\section{References}

Becker, B. E., \& Huselid, M. A. (1998). High performance work systems and firm performance: A synthesis of research and managerial implications. In G. R. Ferris (Ed.), Research in Personnel and Human Resource Management, vol. 16: 53-101. Greenwich, CT: JAI Press.

Cook, D. \& Campbell, D. (1979). Quasi-Experimentation. Holt-Rinehart: New York.

Delaney, J.T., \& Huselid, M.A. 1996. The impact of human resource management practices on perceptions of organizational performance. Academy of Management Journal, 39: 949969.

Delery, J.E. (1998). Issues of fit in strategic human resource management: Implications for research. Human Resource Management Review, 8: 289-310.

Delery, J.E., and Doty, D.H. (1996). Modes of theorizing in strategic human resource management: Tests of universalistic, contingency and configurational performance predictions'. Academy of Management Journal 39: 802-835

Dyer, L \& Reeves, T. (1995). HR strategies and firm performance: What do we know and where do we need to go. International Journal of Human Resource Management 6: 656-670.

Drucker, P. (1954). The Practice of Management. New York: Harper \& Row.

Fulmer, B., Gerhart, B., and Scott, K. (2003). Are the 100 Best better? An empirical investigation of the relationship between being a "Great Place to Work" and firm performance. Personnel Psychology, 56, 965-993.

Gardner, T., \& Wright, P. (2002). The HR - firm performance relationship: Is it only in the mind of the beholder? Center for Advanced Human Resource Studies Working paper, Cornell University, Ithaca, NY..

Gerhart, B. (2004). Research on Human resources and effectivness: Selected methodological challenges. Paper presented at the conference "HRM: What's Next?", Erasmus University, Rotterdam, the Netherlands.

Gerhart, B., \& Milkovich, G. (1990). Organizational differences in managerial compensation and financial performance. Academy of Management Journal, 33: 663-691.

Gerhart, B., Wright, P. M., McMahan, G. C., \& Snell, S. A. (2000). Measurement error in research on human resources and firm performance: How much error is there and how does it influence effect size estimates? Personnel Psychology, 53: 803-834.

Guest, D., Michie, J., Conway, N., \& Sheehan, M. (In Press). A study of human resource management and corporate performance in the UK. British Journal of Industrial Relations

Guthrie, J. (2001). High Involvement work practices, turnover, and productivity: Evidence from New Zealand. Academy of Management Journal, 44: 180-192.

Harter, J., Schmidt, F., \& Hayes, T. (2002). Business-unit-level relationship between employee satisfaction, employee engagement, and business outcomes: A meta-analysis. Journal of Applied Psychology, 87, 268-279.

Hofmann, D.A. (2002). Issues in multilevel research: Theory Development, Measurement, and Analysis. In S. G. Rogelberg (Ed.), Handbook of research methods in industrial and organizational psychology (pp. 247-274). Malden, MA: Blackwell.

Hutchison, S., Kinney, N., \& Purcell, J. (2002). Bringing policies to Life: discretionary behavior and the impact on business performance. Paper presented at the Bath Conference, University of Bath School of Management, 10-11 April.

Huselid, M.A. (1995). The impact of human resource management practices on turnover, productivity, corporate financial performance. Academy of Management Journal, 38 : 635-672. 
Huselid, M. A. \& Becker, B. E. (1996). Methodological issues in cross-sectional and panel estimates of the human resource-firm performance link. Industrial Relations, 35: 400422.

Huselid, M. A. \& Becker, B. E. (2000). Comment on measurement error in research on human resources and firm performance: How much error is there and how does it influence effect size estimates? Personnel Psychology, 53: 835-854.

Ichniowski C., Shaw, K \& Prennushi, G. (1997). The effects of human resource management practices on productivity. American Economic Review, 87: 291-313.

Koys, D. (2001). The effects of employee satisfaction, organizational citizenship behavior, and turnover on organizational effectiveness: a unit-level, longitudinal study. Personnel Psychology, 54:1 101-114.

MacDuffie, J.P. (1995). Human resource bundles and manufacturing performance: Organizational logic and flexible production systems in the world auto industry. Industrial and Labor Relations Review, 48: 197-221.

Meyer, J. P., \& Allen, N. J. (1997). Commitment in the Workplace: Theory, Research, and Application. Thousand Oaks, CA: Sage Publications.

Porter, L. W., Steers, R. M., Mowday, R. T., \& Boulin, P. V. (1974). Organizational commitment, job satisfaction, and turnover among psychiatric technicians. Journal of Applied Psychology, 59: 603-609.

Rogers, E. W., \& Wright, P. M. (1998). Measuring organizational performance in strategic human resource management: Problems, prospects, and performance information markets. Human Resource Management Review, 8: 311-331.

Rowe, W. G. \& Wright, P. M. (1997). Related and unrelated diversification and their effect on human resource management controls. Strategic Management Journal, 18: 329-338.

Ryan, AM, Schmit, MJ, \& Johnson, R. (1996). Attitudes and effectiveness: Examining relations at an organizational level. Personnel Psychology, 49, 853-882.

Schneider, B., Hanges, P., Smith, B., \& Salvaggio, A. (2003). Which comes first: employee attitudes or organizational financial and market performance. Journal of Applied Psychology, 88, 836-851.

Snell, S., \& Dean, J. (1994). Integrated manufacturing and human resource management: The moderating effects of jobs and organizational inertia. Academy of Management Journal, 37: 1109-1140.

Stewart, T. (1996). Taking on the last bureaucracy. Fortune, 133(1): 105, 106, 108.

Watson Wyatt (2002). Human Capital Index ${ }^{\circledR}$ : Human Capital As a Lead Indicator of Shareholder Value.

Wright, P., \& Gardner, T. (2003). Theoretical and empirical challenges in studying the HR practice - firm performance relationship. In D. Holman, T.D. Wall, C. Clegg, P. Sparrow, and A. Howard (Eds.), The New Workplace: People Technology, and Organisation, Sussex, UK: John Wiley and Sons.

Wright, P., Gardner, T., Moynihan, L., Park, H., Gerhart, B. \& Delery, J. (2001). Measurement error in research on human resources and firm performance: Additional data and suggestions for future research. Personnel Psychology, 54: 875-902.

Youndt, M., \& Snell. S. (1995). Human resource management and firm performance: Testing a contingency model of executive controls. Journal of Management, 21: 711-737.

Youndt, M.A., Snell, S A., Dean, J.W., and Lepak, D.P. (1996). Human Resource management, manufacturing strategy, and firm performance, Academy of Management Journal, 39: 836-866. 